\title{
Seroconversion of reticulin autoantibodies predicts coeliac disease in insulin dependent diabetes mellitus
}

\author{
M Mäki, T Huupponen, K Holm, O Hällström
}

\begin{abstract}
Serum IgA class reticulin autoantibody test was performed prospectively once a year on 238 children and adolescents with insulin dependent diabetes mellitus (IDDM). At the initial testing, within one year after onset of IDDM, five were positive and 233 were negative. During follow up a further 11 of the initially antibody negative children became positive $(6 \cdot 7 \%)$. Jejunal biopsy was performed at the appearance of the autoantibodies and silent coeliac disease was shown in nine $(3 \cdot 8 \%)$. One of these children showed on initial biopsy after the onset of IDDM to have normal jejunal mucosal architecture deteriorating later to a flat lesion. Jejunal immunohistochemical studies of another of the patients positive for reticulin autoantibodies but normal on routine biopsy showed an increased density of intraepithelially located gamma/delta $T$ cells and aberrant HLA-DR expression in the crypts pointing to ongoing mucosal inflammation and potential coeliac disease. This study shows that in IDDM patients, reticulin autoantibody negative subjects become antibody positive, which may be followed by coeliac disease. Repeated serological screening and rebiopsy should be considered to detect late developing clinically silent coeliac disease among patients with IDDM.

(Gut 1995; 36: 239-242)
\end{abstract}

Keywords: coeliac disease, diabetes mellitus, screening, gluten sensitive enteropathy.

Serum IgA class reticulin antibodies tested on either rodent ${ }^{1-3}$ or primate tissues, ${ }^{2-5}$ have been shown to be a sensitive and specific method in detecting untreated clinically silent coeliac disease. These autoantibodies disappear with mucosal healing, and during gluten challenge their reappearance predicts mucosal relapse. In a previous study, reticulin antibodies were found to be positive in $4 \cdot 2 \%$ of children with insulin dependent diabetes mellitus (IDDM) ${ }^{6}$ Some of the children positive for the autoantibodies did not have flat mucosa compatible with coeliac disease and a diagnosis of coeliac disease was considered to be excluded. On the other hand, late developing mucosal atrophy in coeliac disease (latent coeliac disease) seems to be more common than previously assumed. ${ }^{7-13}$ We have also recently learned that a posi- tive reticulin antibody test not only predicts undiagnosed silent coeliac disease in symptomless first degree relatives of coeliac disease patients, but also finds a small number of relatives with normal mucosal architecture expressing coeliac type HLA haplotypes. Some of these health subjects have, during clinical follow up, been shown to develop overt coeliac disease. ${ }^{14}$

In this prospective study we now show that retesting for reticulin antibodies and follow up biopsy shows late developing jejunal mucosal atrophy among IDDM patients.

\section{Patients and methods}

The study included all 238 children with IDDM who were less than 18 years of age and who were attending the paediatric outpatient clinic at the University Hospital of Tampere. All children had received normal gluten containing food since early infancy.

In 1984, a yearly screening programme for coeliac disease among patients suffering from IDDM was started and serum samples taken for reticulin autoantibody measurements. During the years the range from onset of diabetes to the time when the first serum sample of the children concerned was drawn varied from 0 to 12 months. Both the patients and their parents were informed as to the study programme, which included small bowel biopsy at the appearance of reticulin antibodies. The study programme was ethically accepted by the University Hospital of Tampere.

Serum IgA class $R 1$ type reticulin antibodies were measured by means of indirect immunofluorescence with rat kidney and liver tissues as substrates. ${ }^{12}$ Positivity meant typical R1 staining pattern in both tissues. Jejunal suction biopsy was performed with a paediatric or adult size Watson capsule. The serum reticulin autoantibody titre concentrations were followed up during the gluten free diet treatment.

The biopsy specimens were studied morphometrically (villous height, crypt depth, intraepithelial lymphocyte count/100 epithelial cells). Immunohistochemical stainings were performed in one reticulin antibody positive patient having normal jejunal mucosal morphology as previously published. ${ }^{15} 16$

\section{Results}

During the study 16 of $238(6 \cdot 7 \%)$ children with diabetes had a positive IgA class reticulin autoantibody titre $(1: \geqslant 5)$ but 11 of them were 


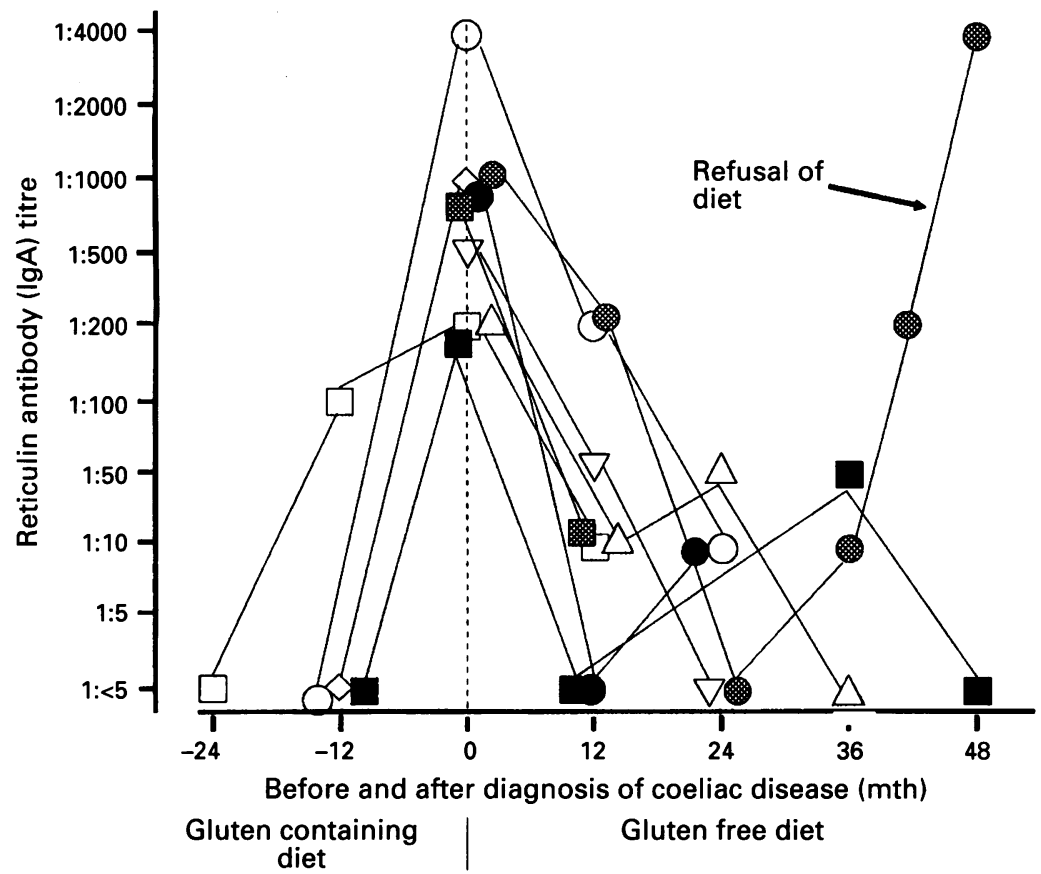

Figure 1: Serum reticulin IgA class autoantibody titres of patients after onset of insulin dependent diabetes mellitus before (gluten containing diet) and after the diagnosis of coeliac disease (gluten free diet). presented, one with subsequently confirmed latent coeliac disease and the other with mucosal findings suggesting coeliac disease latency. On initial biopsy they both showed normal villous architecture excluding coeliac disease.

Both children had received gluten from early infancy and they were negative for reticulin autoantibodies (IgA class titre $1:<5$ ) at onset of IDDM. They had experienced no abdominal symptoms and their growth charts showed no deviations in weight or height. One year later the reticulin antibody titre was $1: 100$ in one of them. Small bowel biopsy showed normal villous architecture and the boy was considered not to have coeliac disease and normal gluten containing diet continued. One year later the IgA class reticulin antibody titre was 1:200. A new biopsy showed totally flat mucosa with crypt hyperplasia. He had had no abdominal symptoms. Gluten free diet was started resulting in disappearance of reticulin antibodies. The other child became first time positive (titre 1:50) five years after onset of IDDM. On biopsy examination the mucosa was normal. A negative seroconversion was seen a year later and further follow up while receiving a gluten containing diet showed a rise in serum reticulin antibody titre $(1:<5-1: 50-$ $1: 100)$. Coeliac disease was again excluded as the biopsy specimen showed high normal villi. Immunohistochemical studies showed, however, aberrant HLA-DR expression in crypt epithelial cells and a 10-fold increased density of intraepithelially located gamma/delta $\mathrm{T}$ cells (Fig 2). (median 1:1000) in those nine children, with small, flat intestinal mucosa compared with the seven found to have normal jejunal mucosal architecture (median 1:10, range 1:5 to $1: 500$ ). The mean time between onset of diabetes and finding of positive reticulin antibody titre values was 13 months in the group with coeliac disease. In those with low titres of reticulin antibodies and normal on biopsy examination, the elapsed mean time was 3.4 years. It should be remembered that the antibody testing was performed only once a year.

In four of the children found to have enteropathy compatible with coeliac disease together with a positive reticulin antibody test, an earlier antibody test after onset of diabetes had been negative (Fig 1). With negative screening test results and absence of symptoms, these children did not have a biopsy at the time of first screening. Routine retesting according to protocol showed a switch to positivity, and on biopsy examination the mucosal histology was that typical for coeliac disease. Eight of nine children had experienced no abdominal symptoms (silent coeliac disease). During gluten free diet IgA class reticulin autoantibody titres fell in all nine patients (Fig 1). One 13 year old girl refused further gluten free diet, resulting in an increase in the serum titres $(1:<5-1: 10-1: 200-1: 4000)$.

POTENTIAL COELIAC DISEASE

In Fig 2 two children with IDDM included in the subgroup with potential coeliac disease are

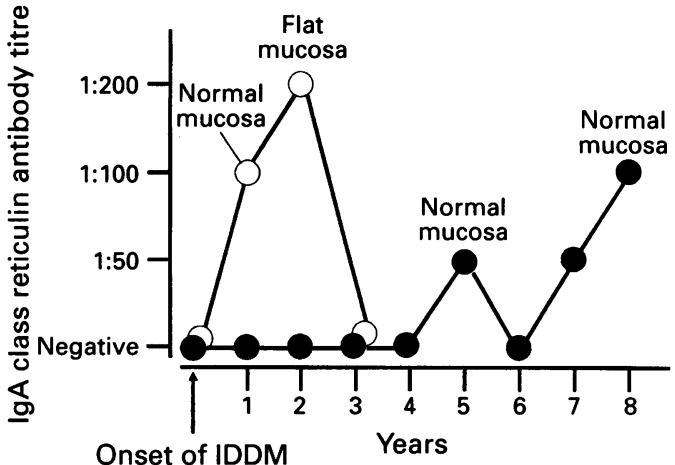

Figure 2: Serial serum IgA class reticulin autoantibody titres in an 8 year old boy (open circles) and 11 year old girl (black circles) after the onset of insulin dependent diabetes mellitus (IDDM). Both had received a gluten containing normal diet from early infancy. Biopsy was performed for the first time when the antibodies turned positive. Morphometric results are described. First normal jejunal biopsy of the boy: villous height $315 \mu \mathrm{m}$, crypt depth $166 \mu \mathrm{m}$, intraepithelial lymphocyte count $37 / 100$ epithelial cells. Second biopsy of the boy: rebiopsy one year later showed totally flat mucosa. First normal jejunal biopsy of the girl: villous height $415 \mu \mathrm{m}$, crypt depth $91 \mu \mathrm{m}$, intraepithelial lymphocyte count 19/100 epithelial cells. Second normal biopsy of the girl: villous height $456 \mu \mathrm{m}$, crypt depth $91 \mu \mathrm{m}$, intraepithelial lymphocyte count 23/100 epithelial cells. Immunohistochemical staining of intraepithelial T cells (95\% confidence intervals for controls, ref 15): alpha/beta 16.8 cells/mm (14 to 21), staining extending to crypt epithelial cells (crypts negative in controls, ref 16). gammaldelta $14.7 \mathrm{cells} / \mathrm{mm}(0 \cdot 8$ to 1.9$)$. Strong $H L A-D R$ 


\section{Discussion}

The association between IDDM and coeliac disease is clinically well established in both children and adults, ${ }^{6}{ }^{17-21}$ and both diseases have their susceptible genes in the HLA-DQ region. ${ }^{22} 23$ Only occasionally does coeliac disease precede the onset of IDDM; more often coeliac disease is diagnosed shortly or years after the onset of IDDM.$^{621}$ In this way these patients differ from classic coeliac disease, which presents with a malabsorptive syndrome and diagnosis made at an early age. Their disease resembles more the situation seen in Finland and many western European countries where a changing pattern towards milder symptomatology of both childhood and adult coeliac disease has been noticed.

We have earlier shown that serum reticulin autoantibodies disappear in parallel with biopsy confirmed mucosal healing in patients with IDDM and clinically silent coeliac disease treated with a gluten free diet. ${ }^{6} 21 \mathrm{We}$ consider the patients in our new series with total flat mucosa and crypt hyperplasia to suffer also from coeliac disease as in these patients serum reticulin autoantibodies also disappeared with a gluten free diet. The more liberal diagnostic approach used today is appropriate especially in children with diabetes and in accordance with the revised criteria of the European Society for Pediatric Gastroenterology and Nutrition for diagnosis of coeliac disease. ${ }^{24}$

This study shows the prevalence of reticulin autoantibodies in IDDM to be $1: 15$ and that of coeliac disease 1:26. These figures are significantly higher than the prevalence of coeliac disease $(1: 1000)$ in the Finnish childhood population. Seropositivity in diabetes $(6 \cdot 7 \%)$ is significantly higher, even than in children clinically suspected for coeliac disease $(2 \cdot 0 \%)$. IgA class fully R1 type reticulin autoantibody positivity mostly means undiagnosed coeliac disease (sensitivity $97 \%$, specificity 98\%), ${ }^{1-3} 14$ or latency of coeliac disease. .11 $^{1314}$

Our results show that in IDDM reticulin autoantibodies are often formed only after the onset of the disease. Histological proof of the existence of latent coeliac disease in diabetes is given in one patient. The first biopsy specimen was not entirely normal but presented an 'infiltrative/hyperplastic' picture. ${ }^{25}$ Catassi et al ${ }^{12}$ also recently described a case of latent coeliac disease in diabetes. It is presumed, knowing the value of the serum IgA class reticulin autoantibody test, that the three other silent coeliac disease cases positive for reticulin antibody test at the time of mucosal atrophy had normal mucosal architecture at the time when the test was negative. Five of 16 seropositive patients were picked up at the initial screening ( 0 to 12 months after onset of IDDM). Thus in these patients the enteropathy may have preceded onset of IDDM.

We have recently reported that late developing mucosal atrophy (latent coeliac disease) may be shown in coeliac disease and we assume it to be more common than previously thought. Thus, normal mucosal architecture on biopsy examination would not always exclude coeliac disease, as was the case in our patient with IDDM. Flat mucosa with crypt hyperplasia can develop later.

An intriguing question is whether the seven patients with diabetes with low titres of IgA class reticulin antibodies and normal jejunal biopsy may all have latent coeliac disease. In fact, one of them showed evidence of gluten induced mucosal inflammation expressed as aberrant upregulation of HLA-DR molecules in crypt epithelial cell. ${ }^{1626}$ Also, increased density of intraepithelial gamma/delta $T$ cell receptor bearing lymphocytes suggests coeliac disease latency..$^{11} 1527$ It is also possible that in these patients coeliac disease with enteropathy never develops, but that other gluten sensitive diseases emerge instead. The classic example is dermatitis herpetiformis, where the gluten induced skin disease may develop in genetically susceptible subjects without enteropathy, but with a high density of gamma/delta T cells in normal mucosa. ${ }^{28}$ It is also possible that no gluten sensitive disease ever arises.

It is not known what other factors in addition to gluten are needed to initiate reticulin autoantibody production and development of mucosal atrophy in IDDM, that is in older children who have ingested gluten for years. The answer most probably is an HLA associated defect in cellular immunity, but again, why do reticulin autoantibody seroconversions occur after the onset of diabetes? It is possible that in addition to gluten some infection could break the tolerance or that an increase in gluten ingestion after the onset of diabetes could be the explanation.

In conclusion, we have obtained new information on the natural history of coeliac disease. Following up children and adolescents after onset of IDDM we showed seroconversion of reticulin autoantibodies followed by jejunal mucosal deterioration. Potential coeliac disease $^{29}$ in subjects with normal jejunal morphology may be shown by immunohistochemical studies. Screening and biopsy of IDDM patients only once is not sufficient to exclude coeliac disease on the criterion of normal mucosa. Repeated serological screening with specific autoantibody tests is necessary, followed by a new biopsy. In the case of normal biopsy findings, development of malabsorptive features or increase in serum autoantibody titres may be the indication for further re-evaluation. In this way the development of coeliac disease with enteropathy may be detected early and properly treated.

The Coeliac Disease Study Project is supported by the Medical Research Council, Academy of Finland (research contract no 1061289) and by the Sigrid Jusélius Foundation.

1 Mäki M, Hällström O, Vesikari T, Visakorpi JK. Evaluation of a serum IgA-class reticulin antibody test for the detection of childhood coeliac disease. F Pediatr 1984; 105: 901-5 2 Hällström $O$. Comparison of IgA-class reticulin and endomysium antibodies in coeliac disease and dermatitis herpetiformis. Gut 1989; 30: 1225-32.

3 Unsworth DJ, Brown DL. Serological screening suggests that adult coeliac disease is underdiagnosed in the UK and increases the incidence by up to $12 \%$. Gut $1994 ; 35$ : $61-4$.

4 Kárpáti S, Burgin-Wolff A, Krieg T, Meurer M, Stolz W, Braun-Falco O. Binding to human jejunum of serum IgA antibody from children with coeliac disease. Lancet 1990; 336: $1335-8$.

5 Chorzelski TP, Sulej J, Tschorzewska H, Jablonska S, Beutner EH, Kumar V. IgA class endomysium antibodies in dermatitis herpetiformis and coeliac disease. Ann NY Acad Sci 1983; 420: 325-34. 
6 Mäki M, Hällström O, Huupponen T, Vesikari T, Visakorpi $\mathrm{JK}$. Increased prevalence of coeliac disease in diabetes. Arch Dis Child 1984; 59: 739-42.

7 Weinstein WM. Latent celiac sprue. Gastroenterology 1974; 66: 489-93.

8 Doherty M, Barry RE. Gluten induced mucosal changes in subjects without overt small-bowel disease. Lancet 1981; i: 517-20

9 Ferguson A, Blackwell JN, Baretneson RStC. Effects of additional dietary gluten on the small-intestinal mucosa of volunteers and of patients with dermatitis herpetiformis. Scand f Gastroenterol 1987; 22: 543-49.

10 Mäki M. Holm K, Koskimies S, Visakorpi JK. Normal small bowel biopsy followed by coeliac disease. Arch Dis Child 1990; 65: 1137-41.

11 Mäki M, Holm K, Collin P, Savilahti E. Increase in gamma/delta $\mathrm{T}$ cell receptor bearing lymphocytes in normal small bowel mucosa in latent coeliac disease. Gut 1991; 32: 1412-4.

12 Catassi C, Natalini G, Rätsch IM, Gabrielli O, Coppa GV, Giorgi PL. Documented latent coeliac disease in a child with insulin-dependent diabetes mellitus. Eur $f$ Pediatr 1991; 150: 832-4

13 Collin $\mathrm{P}$, Helin H, Mäki M, Hällström O, Karvonen AL Follow-up of patients positive in reticulin and gliadin antibody tests with normal small-bowel biopsy findings. Scand f Gastroenterol 1993; 28: 595-8.

14 Mäki $M$, Holm K, Lipsanen V, Hällström $O$, Viander $M$, Collin P, et al. Serological markers and HLA genes among healthy first-degree relatives of patients with coeliac disease. Lancet 1991; 338: 1350-3.

15 Holm K, Mäki M, Savilahti E, Lipsanen V, Laippala $P$, Koskimies S. Intraepithelial gamma/delta T-cell-receptor
lymphocytes and genetic susceptibility to coeliac disease. lymphocytes and genetic susc
Lancet $1992 ; 339: 1500-3$.

16 Holm K, Savilahti E, Koskimies S, Lipsanen V, Mäki M. Immunohistochemical changes in the jejunum in firstdegree relatives of coeliac patients and the coeliac disease marker DQ genes. HLA class II antigen expression, interleukin-2-receptor-positive cells and dividing crypt cells. Gut 1994; 35: 55-60.

17 Savilahti E, Simell O, Koskimies S, Rilva, A, Åkerblom HK. Coeliac disease in insulin-dependent diabetes mellitus. f Pediatr 1986; 108: 739-42.

18 Cacciari E, Salardi S, Volta U, Biasco G, Partsotti S, Mantovani A, et al. Prevalence and characteristics of coeliac disease in type I diabetes mellitus. Acta Paediatr Scand 1987; 76: 671-2.

19 Koletzko S, Burgin-Wolff A, Koletzko B, Knapp M, Burger $\mathrm{W}$, Gruneklee D, et al. Prevalence of coeliac disease in diabetic children and adolescents. A multicentre study. Eur f Pediatr 1988; 148: 113-7.

20 Barera G, Bianchi C, Calisti L, Cerutti F, Dammacco F, Frezza E, et al. Screening of diabetic children for coeliac disease with antigliadin antibodies and HLA typing. Arch Dis Child 1991; 66: 491-4.

21 Collin P, Salmi J, Hällström O, Oksa H, Oksala H, Mäki M, et al. High frequency of coeliac disease in adult patients with type-I diabetes. Scand 7 Gastroenterol 1989; 4: 81-4

22 Thomson G, Robinson WP, Kuhner MK, Joe $S$, MacDonald MJ, Gottschall JL, et al. Genetic heterogeneity, modes of inheritance, and risk estimates for a joint ity, modes of inheritance, and risk study of Caucasians with insulin-dependent diabetes
mellitus. Am $\mathcal{F}$ Hum Genet 1988; 43: 799-816.

23 Sollid LM, Thorsby E. HLA susceptibility genes in celiac disease; genetic mapping and role in pathogenesis. Gastroenterology 1993; 105: 910-22.

24 Walker-Smith JA, Guandalini S, Schmitz J, Shmerling DH, Visakorpi JK. Revised criteria for diagnosis of coeliac disease. Report of working group of European Society of Paediatric Gastroenterology and Nutrition. Arch Dis Child 1990; 65: 909-11.

25 Marsh MN. Gluten, major histocompatibility complex, and the small intestine. A molecular and immunobiologic approach to the spectrum of gluten sensitivity ("celiac sprue'). Gastroenterology 1992; 102: 330-54.

26 Fais S, Maiuri L, Pallone F, De Vincenzi M, De Ritis G, Troncone $R$, et al. Gliadin induced changes in the expression of MHC class II antigens by human small intestinal epithelium. Organ culture studies with coeliac disease mucosa. Gut 1992; 33: 472-5.

27 Savilahti E, Arato A, Verkasalo M. Intestinal gamma/delta bearing $T$ lymphocytes in celiac disease and inflammatory bowel disease in children. Constant increase in celiac disease. Pediatr Res 1990; 28: 579-81.

28 Savilahti E, Reunala T, Mäki M. Increase of lymphocytes bearing the gamma/delta T-cell receptor in the jejunum of patients with dermatitis herpetiformis. Gut 1992; 33: 206-11.

29 Ferguson A, Arranz E, O'Mahoney S. Clinical and pathological spectrum of coeliac disease, active, silent, latent, potential. Gut 1993; 34: 150-1. 